\title{
El rito para acceder al rango de tecuhtli entre los tlaxcaltecas
}

\author{
DANIEL ALATORRE REYES
}

El rito que ejecutaba el tecuhtli se componía de cuatro fases: su presentación pública en el templo del dios patrono, un periodo de ayuno y penitencia de un año, la entrega de insignias de su nuevo rango y una celebración. El rito no sólo involucraba deidades de la guerra, también era notoria la presencia de dioses relacionados con el sol, la tierra y la lluvia, númenes cuya manifestación no era casualidad, pues reflejaban la preocupación de los tlaxcaltecas por alimentarlos para que continuaran ofreciendo sus favores y protección.

PalabRas ClaVe: rito, tecuhtli, Tlaxcala, Camaxtli, guerra

The Rite to Achieve the Rank of Tecuhtli among the Tlaxcaltecs

The rite carried out by the tecuhtli had four phases: his public presentation at the temple of the patron god, a one year period of fasting and penance, the delivery of insignias of his new rank, and a celebration. This rite not only involved gods of war, it was also noticeable the presence of deities related with the sun, the earth and the rain, gods whose manifestation was not a coincidence, because they represented the Tlaxcaltecs' worry about feeding them so that they continued offering their favors and protection.

KEYwoRDs: rite, tecuhtli, Tlaxcala, Camaxtli, war

Daniel Alatorre Reyes 
os ritos de los gobernantes mesoamericanos para ascender al poder conforman un tema que ha llamado la atención de los investigadores modernos. En el caso de los nahuas del Centro de México, los mexicas han sido los más estudiados. El rito ejecutado por el tecuhtli tlaxcalteca ha recibido menos atención, pues los especialistas se han concentrado en otros temas, como la organización política, la economía o la historia social de Tlaxcala. En los estudios sobre el tecuhtli, se ha intentado definir sus atribuciones, pero se ha pasado por alto el rito que efectuaba para acceder a su condición (Carrasco, 1966: 142-145; Gibson, 1991: 26-38; Lockhart, 1999: 152-154; Thouvenot, 2008: 47-61).

Pedro Carrasco (1966: 133-158) se acercó al tema en una serie de comentarios al documento "La orden que los indios tenían en su tiempo para hacerse tecutles", en los que resaltó las similitudes entre el rito del tecuhtli tlaxcalteca y el de otros gobernantes nahuas del Centro de México, pero no profundizó en el análisis de cada etapa del rito para dilucidar sus significados posibles.

Quien ha dedicado más atención a los ritos de los gobernantes nahuas es Guilhem Olivier (2015: 500-506, 537-541, 588, 596). Los mexicas son su objeto de estudio principal. Respecto al rito del tecuhtli tlaxcalteca, el especialista analizó en particular la ceremonia de horadación de la nariz, el significado de la entrega de la banda de cuero rojo y el papel del fuego.

Este artículo tiene por objetivo estudiar las cuatro etapas del rito, el papel de los dioses que se manifestaban en cada una y su interacción con el tecuhtli. También pretende ser un aporte al tema que deriva de una investigación doctoral del rito del tecuhtli tlaxcalteca.

Antes de analizar el rito, se define el concepto. Luego se exponen las fuentes consultadas para su reconstrucción e interpretación, después se explica quién era el tecuhtli en la sociedad tlaxcalteca. Estos tres apartados son breves, pues sólo esbozan el contexto para que los lectores comprendan mejor el tema principal. 


\section{Definición de rito}

Es un concepto desarrollado en la antropología, la etnología y la sociología. Tras un análisis comparativo en estas disciplinas, Jean-Louis Maisonneuve lo define como "un sistema codificado de prácticas, con ciertas condiciones de lugar y de tiempo, poseedor de un sentido vivido y un valor simbólico para sus actores y testigos, que implica la colaboración del cuerpo y una cierta relación con lo sagrado" (1991: 18). ${ }^{1}$

De entre las numerosas definiciones, ésta me parece acorde al rito que se estudia, compuesto por las prácticas de los tetecuhtin, que consistían en seguir los preceptos establecidos por sus dioses durante un tiempo determinado y en lugares específicos. En algunas etapas, el rito remitía a varias historias sagradas que los tetecuhtin actualizaban en cada repetición para hacerlas contemporáneas, pues se ubicaban en términos simbólicos en el tiempo sagrado en el que habían ocurrido (Eliade, 1972: 351). La contribución del cuerpo era sobresaliente. Durante el rito, los tetecuhtin lo transformaban como parte del procedimiento para acceder a su nueva condición. Por último, se relacionaban con el ámbito sagrado, se comunicaban con los dioses por medio de varias prácticas, como las ofrendas, el ayuno y el autosacrificio - extraer sangre de determinadas partes de su cuerpo para ofrendarla a las deidades- Éste era un rito de paso, que tenía el objetivo de transformar la naturaleza de la persona que lo ejecutaba: "los principales actores son separados de las rutinas asociadas a su vida anterior $[\ldots]$, se dan pasos físicos simbólicos decisivos para extinguir los estatutos anteriores [...]. Para promover la muerte y la transfiguración se cambian las ropas y adornos viejos por otros nuevos y se pinta o mutila el cuerpo" (Harris, 1990: 395-398).

\section{Las fuentes}

Para reconstruir el rito, las fuentes principales son documentos escritos provenientes de Tlaxcala y la cuenca de México. Esta documentación no sólo contiene información sobre el proceso para convertirse en tecuhtli, también guarda datos valiosos sobre las deidades que intervenían. Los autores de los documentos son en su mayoría de procedencia española, excepto Diego Muñoz Camargo, mestizo tlaxcalteca que escribió la "Descripción de la ciudad y provincia de Tlaxcala" (1984), en la que relató el rito para acceder al rango de tecuhtli. Sus pasajes guardan mucha similitud con los proporcionados por el fraile franciscano Toribio de Benavente, conocido como Motolinía, quien escribió la obra $\mathrm{Me}$ moriales o Libro de las cosas de la Nueva España y de los naturales de ella (1971).

Otra fuente es el documento "La orden que los yndios tenían en su tiempo para hacerse tecutles", independiente de las obras de Motolinía y Muñoz Camargo, cuyo autor se desconoce. El virrey Antonio de Mendoza envió esta relación a España en 1537 (Carrasco, 1966: 133). ${ }^{2}$ Es un documento breve, que coincide en algunas partes con Motolinía y Muñoz Camargo, y al mismo tiempo aporta datos que esos autores no mencionan. Por su parte, Francisco Cervantes de Salazar (1985: 533-534), en su Crónica de la Nueva España, describe una ceremonia en la que se "armó caballero" al hijo de un tecuhtli llamado Maxixcatzin.

Para Émile Durkheim (1992: 36), los ritos son reglas de conducta que prescriben cómo debe comportarse el hombre en relación con las cosas sagradas. Como se verá, el tecuhtli debía adoptar ciertos comportamientos para interactuar con las deidades que se manifestaban en las fases del rito.

2 Publicado por Pedro Carrasco en el artículo "Documentos sobre el rango de tecuhtli entre los nahuas tramontanos". Cuando se cite esta fuente, se hará referencia a Carrasco (1966). 
Las crónicas de los conquistadores españoles Hernán Cortés y Bernal Díaz del Castillo también proporcionaron información. El primero escribió las Cartas de relación (1960) y el segundo la Historia verdadera de la conquista de la Nueva España (1960). Estas obras no describen el rito, pero aportan datos relevantes sobre el papel de los tetecuhtin en la sociedad tlaxcalteca porque los autores fueron testigos presenciales de su modo de vida. La Historia de las indias de Nueva España e islas de la tierra firme, del fraile dominico Diego Durán (1967), revela información sobre Camaxtli, el dios patrono de Tlaxcala que se manifestaba durante el rito.

En conjunto, las obras y autores mencionados recuperan información sumamente útil para intentar reconstruir e interpretar el rito a partir de las noticias sobre el ceremonial, el papel de los tetecuhtin en Tlaxcala y la importancia del dios patrono. Aunque los autores son españoles o mestizos, registraron en sus obras parte de la tradición indígena tlaxcalteca, pues se valieron de fuentes orales y códices, e incluso algunos fueron testigos presenciales de lo que anotaron.

Respecto a las fuentes iconográficas, el Lienzo de Tlaxcala, el Lienzo de Tepeticpac, el Códice Borgia y la Historia Tolteca-Chichimeca complementan los datos de los documentos escritos, en particular en lo relativo a los distintivos de poder que recibían los tetecuhtin. Las dos últimas no son de procedencia tlaxcalteca, pero son importantes porque contienen representaciones del dios patrono de Tlaxcala e iconografía sobre la ceremonia de la horadación de la nariz de los gobernantes.

\section{Los tetecuhtin}

Según Motolinía (1971: 339), el rango de tecuhtli — también teuctli o tecuitli- era el mayor en la escala social de Tlaxcala. Por su descripción del rito de estos personajes, se aprecia que al concluirlo adquirían funciones militares, judiciales, religiosas, políticas y administrativas. Este personaje era el gobernante de un teccalli, o casa de gobierno, es decir, de una unidad política (López, 1985: II, 154) que disponía de tierras y personas del común que daban tributo y servicios al tecuhtli (Carrasco, 2000: 171). Los principales de linaje, mercaderes, sacerdotes y guerreros podían alcanzar este rango.

En su análisis del término, Marc Thouvenot (2008: 60-61) concluye que el rango tenía más el sentido de juez y señor. En el primer caso, una manera de llamar a los jueces era teuctlato, cuya raíz es teuc, la misma que en teuctli, que se traduce como "principal o señor" (Molina, 1970: fol. 93v). El otro componente es el verbo tlatoa, hablar, por lo que la traducción sería "principal o señor que habla", en alusión a su autoridad como juez. En el segundo caso, Thouvenot (2008: 59) dice que el sentido de señor corresponde a la tradición más común que hoy se encuentra en las traducciones de las fuentes.

El tecuhtli recibía su cargo de los dioses y participaba en actos de dirección y gobierno (Thouvenot, 2008: 59). De acuerdo con Motolinía, los que ostentaban ese dictado "tenían entre otras preeminencias, que en los concilios y ayuntamientos sus votos eran principales, y en las fiestas hacían más cuenta de ellos" (1971: 344). Los conquistadores españoles Cortés y Díaz del Castillo, que estuvieron en Tlaxcala, confirman que podían reunirse para discutir temas concernientes a asuntos de gobierno:

La orden que hasta ahora se ha alcanzado que la gente de ella tiene en gobernarse, es casi como las señorías de Venecia y Génova o Pisa, porque no hay señor general de todos. Hay muchos señores y todos residen en esta ciudad, y los pueblos de la tierra son labradores y son vasallos de estos señores, y cada uno tiene su tierra por sí; tienen unos más que otros, y para sus guerras que han de ordenar júntanse todos, y todos juntos las ordenan y conciertan (Cortés, 1960: 41). 
Según este pasaje, los tetecuhtin podían tomar parte en asuntos importantes relacionados con el gobierno de sus territorios, como la guerra. Otro ejemplo del papel del tecuhtli en la sociedad tlaxcalteca es su encuentro con Xicoténcatl a las afueras de Tlaxcala para negociar la paz y la entrada de los españoles a su territorio. Cortés menciona que el líder militar llegó acompañado de 50 personas principales (1960: 40). Díaz del Castillo (1960: 116) señala que dos tetecuhtin, Xicoténcatl el viejo, padre de Xicoténcatl el mozo, y Maxixcatzin convocaron a todos los “caciques y capitanes" que había en sus poblaciones para discutir la conveniencia de aliarse o no con los españoles. Ni Motolinía ni los conquistadores aclaran cuántos tetecuhtin había en los cuatro altepetl principales que conformaban Tlaxcala. ${ }^{3}$ Aunque Cortés menciona 50, es posible que hayan sido más.

En lo relativo al rango de tecuhtli, Muñoz Camargo menciona que las personas que "habían ganado alguna cosa en la guerra, o que hubiesen hecho y emprendido casos señalados y aventajados, o como tuviese indicios de mucho valor les armaban caballeros" (1984: 149). El cronista distingue entre los mercaderes y los principales de linaje, pues a los primeros se les llamaba tepilhuan ${ }^{4} \mathrm{y}$ a los segundos, por ser "finos" en su descendencia, se les llamaba tecuhtli. Si nos atenemos a sus títulos, podemos inferir que los tetecuhtin estaban arriba de los tepilhuan, pues este término se refiere a su condición de hijos de la gente, es decir, a las personas comunes conocidas como macehualtin, que no pertenecían a un linaje prestigioso.

En este pasaje se aprecia que una forma de acceder al cargo era por méritos propios y que los macehualtin distinguidos eran elegibles. Sin embargo, los tetecuhtin pertenecientes a linajes importantes lo obtenían por herencia directa o eran designados por un grupo de principales dentro del linaje (Carrasco, 1966: 146; Lockhart, 1999: 153). Era común que su sucesión fuera por la línea varonil y que el hijo mayor de la esposa principal o legítima fuera elegido como el heredero (Gibson, 1991: 19). En caso de que no hubiera hijos, se daba por sucesión fraterna (Lockhart, 1999: 153).

Antes de avanzar, conviene explicar la organización territorial tlaxcalteca, para que el lector discierna dónde se llevaba a cabo el rito, pues los documentos no mencionan un altepetl específico. En la época prehispánica, el actual estado de Tlaxcala estaba conformado por varios territorios autónomos, los altepeme, que se agruparon en una confederación con el objetivo de permanecer independientes del dominio mexica (García y Merino, 1997: 232). Este concepto se refiere en primer lugar a un territorio, pero sobre todo a una organización de personas que domina ese territorio (Lockhart, 1999: 27). No significaba ciudad en el sentido actual, era una denominación que se daba a cualquier cuerpo político establecido, grande o chico, que tenía un territorio, tradición y gobierno propios (García, 2011: 66). Los altepeme principales y más conocidos eran Ocotelulco, Quiyahuiztlan, Tepeticpac y Tizatlan, que aparecen representados en el Lienzo de Tlaxcala (2016). Como observó René Acuña, el problema de la obra de Muñoz Camargo es que se refiere a los cuatro territorios sin distinción (1984: 19). Cuando describe el rito de los tetecuhtin, no especifica en qué altepetl se llevaba a cabo. Motolinía tampoco establece el lugar, sólo hace referencia a la "provincia de Tlaxcala" (1971: 339-344).

Los datos proporcionados por los documentos escritos permiten suponer que cada tecuhtli efectuaba su rito en el altepetl al que pertenecía y que debió consistir en las mismas ceremonias. A pesar de los

3

Territorios autónomos que conformaban el actual territorio del estado de Tlaxcala, conocidos como altepetl -altepeme en plural-, contracción del difrasismo yn atl yn tepetl, que se traduce como "agua-cerro" (García, 2011: 66).

4 "Hijos de alguien" o "hijos de la gente". La palabra se compone del prefijo indefinido te, "alguien o la gente"; el sustantivo pilli, "hijo", y el sufijo plural posesivo huan (Sullivan, 2014: 49, 55-56). 
problemas que presentan las fuentes, se puede proponer que el rito debió ser el mismo en los altepetl que conformaban Tlaxcala y que éste es el motivo por el cual Motolinía, Muñoz Camargo y "La orden que los yndios tenían en su tiempo para hacerse tecutles" lo describen de manera general sin distinguir entre los territorios confederados.

\section{Comienzo del rito. Presentación del tecuhtli}

Esto ocurría en el templo de Camaxtli, dios que también se llamaba Tlatlauhqui Tezcatlipoca y Mixcóatl (HMP, 1965: 23,36), cuando el tecuhtli empezaba el rito:

Entrados en el patio subían al mancebo a lo alto del templo, y hecho acatamiento a los ídolos, y puesto de rodillas, venía el ministro mayor del templo, y con una uña de águila y con un hueso de tigre delgado como punzón, horadábanle encima de las ventanas de la nariz [...] y allí le ponían unas pedrecitas de azabache negro [...]. Horadarle con uña de águila y con hueso de tigre significaba que en las guerras los que tenían tal dignidad y señorío recibían que eran armados como caballeros, habían de ser en la guerra muy ligeros para seguir y alcanzar a los enemigos, como águilas, y fuertes y animosos para pelear como tigres y leones (Motolinía, 1971: 339). ${ }^{5}$

Esta parte del rito se relacionaba con las responsabilidades militares que adquiría el nuevo tecuhtli. Como menciona el franciscano, se esperaba que sobresaliera en la guerra y mostrara las cualidades de batalla de los animales mencionados. Tal vez, al usar la garra del águila y el hueso del jaguar para perforar la nariz del tecuhtli, se esperaba transmitirle parte de la fuerza de dichos animales, pues se sabe que los nahuas creían que la fuerza vital residía en los huesos (López, 1994: 173). El ceremonial del horadamiento de la nariz fue representado en fuentes iconográficas, como la Historia tolteca-chichimeca (Kirchhoff, Güemes y Reyes, 1976: f. 21r), en la que se aprecia que los futuros gobernantes de otros pueblos hacen esta fase del rito para acceder al poder, como sus homólogos tlaxcaltecas.

Por su parte, "La orden que los yndios tenían en su tiempo para hacerse tecutles" también menciona que el rito comenzaba en el templo de Camaxtli y agrega, a diferencia de Motolinía y Muñoz Camargo, que al recinto llegaban sacerdotes de los templos dedicados a "Tezcatlepuca, Topantecutle, Amoxhutle y Chipe" (Carrasco, 1966: 135). ${ }^{6} \mathrm{La}$ presencia de Tezcatlipoca y Xipe Tótec es muy llamativa, pues eran dioses vinculados a la guerra, como Camaxtli, lo que resalta la importancia de esta actividad para los tlaxcaltecas. $^{7}$

Otro dato mencionado por esta fuente es la presencia de Xiuhtecuhtli, "Xautecle", deidad a la que el tecuhtli ofrecía copal frente a un brasero encendido (Carrasco, 1966). Quizá la presencia de este dios en el rito se debía a que los tlaxcaltecas consideraban el fuego un elemento de cualidad transformadora, que implicaba el cambio de un estado a otro, y un mediador entre el mundo del ser humano y el de los dioses (Limón, 2012: 77-78). Según esta idea, los tetecuhtin empezaban su rito frente al fuego para comenzar su transformación en gobernantes, pero también para comunicarse con las deidades por medio de las ofrendas que eran arrojadas al fuego y consumidas por las llamas (2012: 78).

Muñoz Camargo confirma esta parte en su obra y añade el ofrecimiento de sangre del tecuhtli a Camaxtli (1984: 150). Lo mismo registra "La orden que los yndios tenían en su tiempo para hacerse tecutles" (Carrasco, 1996: 135).

6 Tezcatlipoca, Topantecutle, Amochutle y Xipe Tótec (Olivier, 2015: 476).

$7 \quad$ En el caso de los otros dos dioses, no puedo determinar de momento quiénes eran ni cuál era su papel en el rito, ya que los documentos consultados no dan información sobre ellos. 
Esta situación se asemeja a la ocurrida en Teotihuacan, cuando el dios Nanauatzin se transformó en el Sol. Cuando los dioses lo eligieron, prendieron una hoguera que ardió por cuatro días y la llamaron teotexcalli, "horno divino". Durante ese periodo, Nanauatzin y Tecuciztécatl, el dios que se convirtió en la Luna, ayunaron y se extrajeron sangre del cuerpo como autosacrificio (Sahagún, 1991: 432). Es curioso que Xiuhtecuhtli fuera uno de los dioses que ordenó a Nanuatzin convertirse en el Sol (Leyenda de los soles, 1941: 121) y quien lo transformó cuando se lanzó a las llamas de la hoguera divina. Así como el fuego trastocó a Nanauatzin, el elemento ígneo también modificaba el estado del joven aspirante para convertirlo en tecuhtli durante el rito, de ahí la importancia de iniciarlo ante el dios del fuego.

El rito comenzaba en el templo de Camaxtli, deidad tutelar de Tlaxcala. Durán explica por qué los tlaxcaltecas lo tomaron como patrono: "a este ídolo tenían por dios de la caza [...] porque fue el primero que dio modos y maneras de cazar, y por haber sido muy diestro y astuto en el arte, y el primer señor que los chichimecas y cazadores tuvieron" (1967: I, 71). Su situación era como la de Huitzilopochtli, patrono mexica, pues se le describe como un guía que quizá fuera deificado y cuyas reliquias se conservaron, como mencionan Muñoz Camargo y Durán. El primero dice que se trataba de sus cenizas, divididas entre las cabeceras de Tepeticpac y Ocotelulco (Muñoz, 1984: 163). El segundo señala que en el templo del dios se conservaban instrumentos que le habían pertenecido:

Unas flechas quebradas, viejas, que debían de haber sido de aquel dios, con un arco pequeño. Y así es que aquellas insignias fueron con las cuales guió a los chichimecas [...] a los lugares que agora se hallan, enseñándoles con aquellos instrumentos a buscar la vida por los montes, cuando los trujo y guió a esta tierra. Y así, a honor de este beneficio, guardaban y reverenciaban aquellas insignias como reliquias de alguna cosa divina y del cielo (Durán, 1967: I, 73).

No menciona en cuál de los cuatro altepeme principales estaban las reliquias. Es posible que se hayan dividido y cada uno tuviera alguna reliquia del dios, como en el caso de las cenizas. Es posible que el nuevo tecuhtli quisiera comunicarse con la deidad por medio de esos objetos sagrados, para agradecerle por haber guiado a los tlaxcaltecas desde Chicomoztoc, haberlos instruido en el oficio de la cacería y quizá también por haberlo puesto en el cargo. En otra parte del rito recibía los distintivos que lo acreditaban como miembro del grupo dirigente.

\section{Estado penitencial del tecuhtli}

Cuando el tecuhtli descendía del templo de Camaxtli, se dirigía a un aposento en el que hacía su penitencia. ${ }^{8}$ En el camino, las personas presentes lo increpaban con palabras ofensivas, lo agredían físicamente para probar su paciencia y lo despojaban de su ropa hasta dejarlo en maxtlatl, ${ }^{9}$ único atuendo con el que ingresaba a su lugar de reclusión (Motolinía, 1971: 339). El templo al que ingresaba se llamaba tlamacazcacalco (1971: 340), ${ }^{10}$ que debió ser un recinto en el que se preparaba a los sacerdotes, como sugiere

8 Se entiende por penitencia el conjunto de actividades sacerdotales, como ayuno, autosacrificio, no dormir de noche y sahumar las efigies de los dioses para establecer contacto con su mundo sagrado.

9 Prenda de vestir masculina que consistía en una banda de tela que pasaba sobre la cintura y entre las piernas para cubrir los órganos genitales. Se conoce también como taparrabo.

10 El significado puede ser "en la casa del ofrendador", pues la palabra se compone de tlamacazqui, "ofrendador", y calco, "en la casa". 
su nombre. Motolinía describe que el tecuhtli llevaba a cabo actividades sacerdotales durante su estancia en este lugar:

Luego a la noche le daban un brasero e incensario con su incienso [...] y poníanle delante púas de metl para se sacrificar y ofrecer sangre. Quedaban con él dos o tres hombres diestros en la guerra, que llaman yaotequihua, que también le ayudaban a hacer penitencia. Los cuatro días primeros ninguna cosa dormía de noche; de día asentado dormía un rato no más, todo el otro tiempo tenía delante de si un despertador, y tenía en las manos unas púas de metl, que son como punzones, y en viendo que se iba a dormir, punzábanle ya por las piernas, ya por los brazos hasta le sacar sangre y decíanle: "despierta, que has de velar y tener cuidado de tus [vasallos]; no tomas cargo para dormir sino para velar, y que huya el sueño de tus ojos, y mires por tus criados" (1971: 340).

A la medianoche y al mediodía, se extraía sangre para ofrecerla a Camaxtli. Esto recuerda de nuevo el nacimiento del Sol en Teotihuacan, pues los dioses Nanauatzin y Tecuciztécatl hicieron penitencia cuatro días y cuatro noches. La medianoche fue la hora elegida por los dioses para que se lanzaran al teotexcalli y pudieran convertirse en el Sol y en la Luna (Sahagún, 1991: 432). El tecuhtli pasaba también cuatro días en el tlamacazcacalco, haciendo ayunos y autosacrificios. Sus actos penitenciales no terminaban al salir de ahí, continuaban durante un año:

Acabados los cuatro días, demandaba licencia al gran sacerdote, e iba a acabar su ayuno a los templos de su perroquia [sic], que a su casa no iba, ya que fuese casado no tenía conversación ni con su mujer, ni con otra [...]. Salían a la media noche a lugares que tenían por santos a ofrecer sacrificio; algunas veces al río o algunas fuentes, o encima de algunas sierras do honraban y llamaban a algunos demonios [...], vuelto de su sacrificio, comía una vez a la media noche (Motolinía, 1971: 340-341).

El fraile franciscano compara ese recinto con una parroquia, es decir, con la iglesia que tiene a su cargo la jurisdicción espiritual de un territorio determinado, de lo que inferimos que se refiere a un templo localizado en el poblado del que provenía el tecuhtli.

"La orden que los yndios tenían en su tiempo para hacerse tecutles" menciona que al concluir el ayuno de cuatro días, el cuerpo del tecuhtli era tiznado de negro y confirma que al salir del tlamacazcacalco su penitencia se extendía por un año. La misma fuente da a entender que el tecuhtli sólo estaba pintado de negro durante 35 días, no el año completo: "los Papas le imponían otro nuevo ayuno de treinta días [...] i en estos treinta días, havia de encender nuevo fuego sacado de un palo de que lo sacan, i havia de tener cargo que de día i de noche en estos treinta días no había de cesar el fuego" (Carrasco, 1966: 136-137). ${ }^{11}$

Después de cuidar el fuego 30 días, por órdenes de los sacerdotes debía esperar otros cinco para remover el tizne del cuerpo. Entonces era llevado "á la agua", donde se adoraba a "Chalchitlical", Chalchiutlicue, "que era una mujer i allí en la misma agua hacían sacrificio de las orejas i codornices: echavan en el agua las mejores esmeraldas [...] que tenían y plumajes, i mantas i copal, i todo aquello si era rio lo llevaba ó se hundia" (Carrasco, 1966: 138). Es posible que este lugar sea un río o un manantial en el que se removía el tizne negro.

11 Muñoz Camargo confirma que el tecuhtli estaba tiznado de negro pero extiende el periodo de ayuno de 40 a 60 días (1984: 150-151). Motolinía (1971: 340) menciona que al ingresar al tlamacazcacalco se le daba tinta negra para que la usara en su cuerpo. Los datos sugieren entonces que el tecuhtli usaba pintura corporal negra en dos ocasiones: durante sus cuatro días en el tlamacazcacalco y cuando se trasladaba al templo de su comunidad. 
Entre los sitios que menciona Motolinía (1971: 76) en el pasaje citado, llaman la atención las "sierras". Aunque no mencione los nombres, es posible que una fuera Matlalcueye, La Malinche, donde había un templo de la diosa, considerada el equivalente de Chalchiutlicue en la cuenca de México (Soustelle, 1982: 137-138), por ser una deidad del agua entre los tlaxcaltecas, que además ostentaba el mismo nombre que la montaña. De ser así, el baño ritual del tecuhtli era en un río o manantial en la montaña o cercano.

No debe descartarse la posibilidad de que los tetecuhtin ejecutaran actos sacerdotales, como el autosacrificio, en esa montaña sagrada, pues las diosas del agua y la tierra tenían la misma necesidad de alimento de sangre. Si se acepta que los tetecuhtin hacían parte de su penitencia de un año en ese lugar para ofrendar su sangre a la diosa, entonces los tlaxcaltecas tendrían la misma preocupación sobre la tierra y el agua que otros grupos nahuas, como los mexicas, es decir, estaban conscientes de que debían alimentarlas para que proporcionaran el alimento necesario para la subsistencia humana. En esta parte del rito sobresalían las actividades sacerdotales de los tetecuhtin, lo que permite suponer que entre sus funciones también estaba dirigir el culto a los dioses, junto a los sacerdotes.

El encendido del fuego nuevo y el acto de pintar de negro el cuerpo del tecuhtli durante su penitencia estaban estrechamente vinculados. El primero marcaba el principio de una etapa en la historia de los pueblos y la vida de sus gobernantes (Olivier, 2015: 596). Como se mencionó, el fuego se concebía como un elemento transformador, porque implicaba el cambio de un estado a otro. La acción de pintar de negro el cuerpo tenía dos funciones: representar el estado penitente del tecuhtli y recibir la energía de los dioses con los que era asimilado (Nava, 2009: 111-113).

Mientras tenía el cuerpo tiznado, el tecuhtli hacía actividades sacerdotales, como el ayuno y el autosacrificio, para entablar comunicación con los dioses que intervenían en su rito, principalmente Camaxtli, Xipe Tótec, Tezcatlipoca y Matlalcueye. Para comunicarse con ellos, era necesario que mantuviera encendido el fuego que se le encomendaba, que fungía como mediador entre los seres humanos y los dioses, pues las ofrendas de sangre del tecuhtli les llegarían cuando el fuego las consumiera.

El color negro es característico de Tezcatlipoca y Quetzalcóatl. Es posible que los tetecuhtin fueran asimilados a esos dioses cuando eran pintados de ese color. No considero que fueran comparados con Camaxtli con esta acción porque la pintura corporal de este numen es rayada, propia de las deidades guerreras relacionadas con Venus o Tlahuizcalpantecuhtli, que comparte rasgos con el dios patrono tlaxcalteca, como la pintura corporal rayada y el hecho de que ambos se representan armados con flechas o lanzadardos, lo que hace referencia a su condición de dioses guerreros, como se aprecia en la figura 1 (Olivier, 2015: 408-411).

Hay una referencia a Quetzalcóatl, cuando el tecuhtli es tiznado, pues se dice que al pintarle el cuerpo recibía el nombre de Naxictle, en referencia a su "declaración ayunante" (Carrasco, 1966: 136). Nacxitl era otro nombre de Quetzalcóatl. María del Rosario Nava Román notó que, cuando el dios aparece pintado de negro en códices, es en su manifestación de sacerdote (2009: 51-52). Este color en el cuerpo del tecuhtli lo vincula a Quetzalcóatl en su estado penitencial y con Camaxtli, pues se dice que cuando creó a los chichimecas, ancestros de los tlaxcaltecas, "el Camaxtle hizo penitencia, tomando las púas del maguey, sacándose sangre de la lengua y orejas, y por esto acostumbraban sacarse, de los tales lugares, con las dichas púas, sangre cuando algo pedían a los dioses" (HMP, 1965: 36). Como se aprecia en este pasaje, el numen tlaxcalteca también se vinculaba a los actos penitenciales.

Si la pintura corporal negra fue un símbolo del poder político-religioso entre los nahuas del 


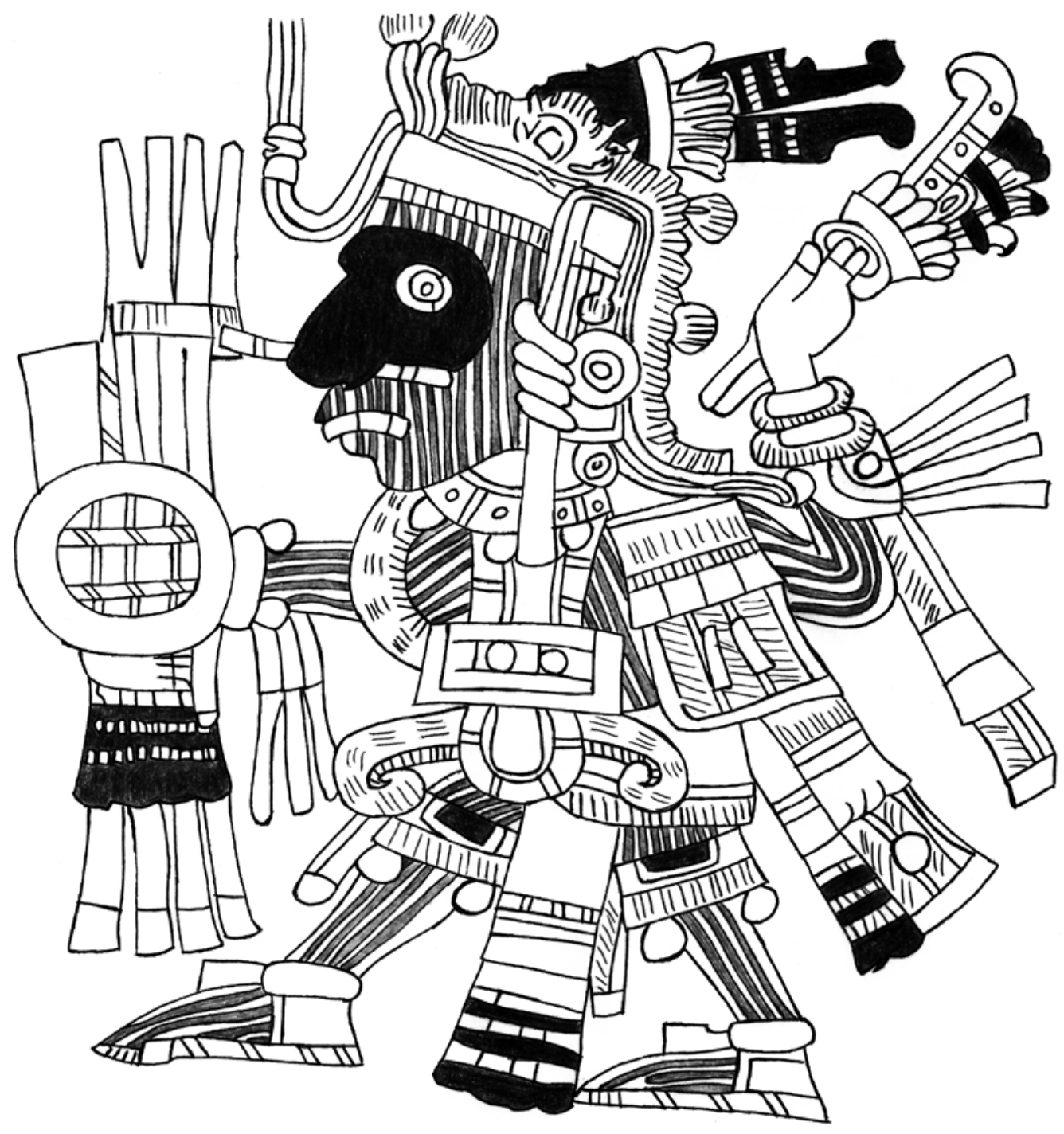

FIGURA 1 - Camaxtli-Mixcóatl, armado con lanzadardos, muestra sus rasgos característicos: pintura corporal rayada, banda roja en la frente y tocado de plumas de águila, conocido como cuauhpilolli. Códice Borgia, lámina 25. Dibujo basado en Olivier (2015: lámina I).

Altiplano Central (Nava, 2009: 111), es posible que los tlaxcaltecas, como otros grupos nahuas, concibieran que el poder provenía de Quetzalcóatl y Tezcatlipoca; quizá por sus vínculos con la deidad suprema Ometéotl eran pintados de color negro, para significar que recibían el poder de esos dioses y no sólo de Camaxtli.
Recibimiento de las insignias de su nuevo rango

Cuando el nuevo tecuhtli terminaba su penitencia de un año, sus familiares comenzaban a preparar el festejo y enviaban mensajes no sólo a parientes, también a otros tetecuhtin. Cuando se reunían, lo llevaban al templo de Camaxtli: 
Desnudábanle la ropa simple que llevaba, y atábanle los cabellos con una correa de cuero colorado, y de esta correa colgaban a los unos lados plumajes o penachuelos; dábanle una manta buena que se cubría, encima echábanle una manta rica [...] en la mano izquierda le daban un arco, y en la derecha le ponían una saeta [...] y entonces le daban el título de su señorío, o le llamaban Xicotencatl tecuitli, o Maxixcacin tecuitli o Chichimecatl tecuitli (Motolinía, 1971: 341-342).

Destacan varios aspectos de esta parte. Acabada la penitencia, volvía al templo del dios patrono, lo que sugiere que era investido con las insignias de poder frente a la estatua del dios, quizá para representar el recibimiento del cargo por parte del numen. En cuanto a su vestimenta, se mencionan adornos de plumas y una manta rica que lo distinguía como tecuhtli. El pasaje de Motolinía es similar a la representación de los tetecuhtin de los cuatro altepetl en el Lienzo de Tlaxcala (2016), en el que se aprecia que, a diferencia de los nahuas de la cuenca, no recibían la xiuhitzolli ni la xiuhtilmatli; ${ }^{12}$ lo único similar en el atuendo eran las piedras en la nariz, que en el caso tlaxcalteca también podían ser de turquesa.

Motolinía menciona que recibían arco y flechas, que además de ser instrumentos chichimecas para la guerra y la caza, eran también reliquias de Camaxtli. Muñoz Camargo señala que provenían de Chicomoztoc y que desde su salida de ese lugar hasta su asentamiento en Tlaxcala fueron conocidos como chichimecas (1984: 140). Durante su migración, fueron guiados por Camaxtli, quien les enseñó a cazar usando arco y flechas. Al morir, sus instrumentos fueron conservados para rendirle culto. Al igual que los mexicas, los tlaxcaltecas también tenían una deuda con el dios patrono que los condujo durante la migración y les entregó un oficio para subsistir. Esta historia explicaría por qué el rito empezaba en el templo del dios y el nuevo tecuhtli se investía frente a él.

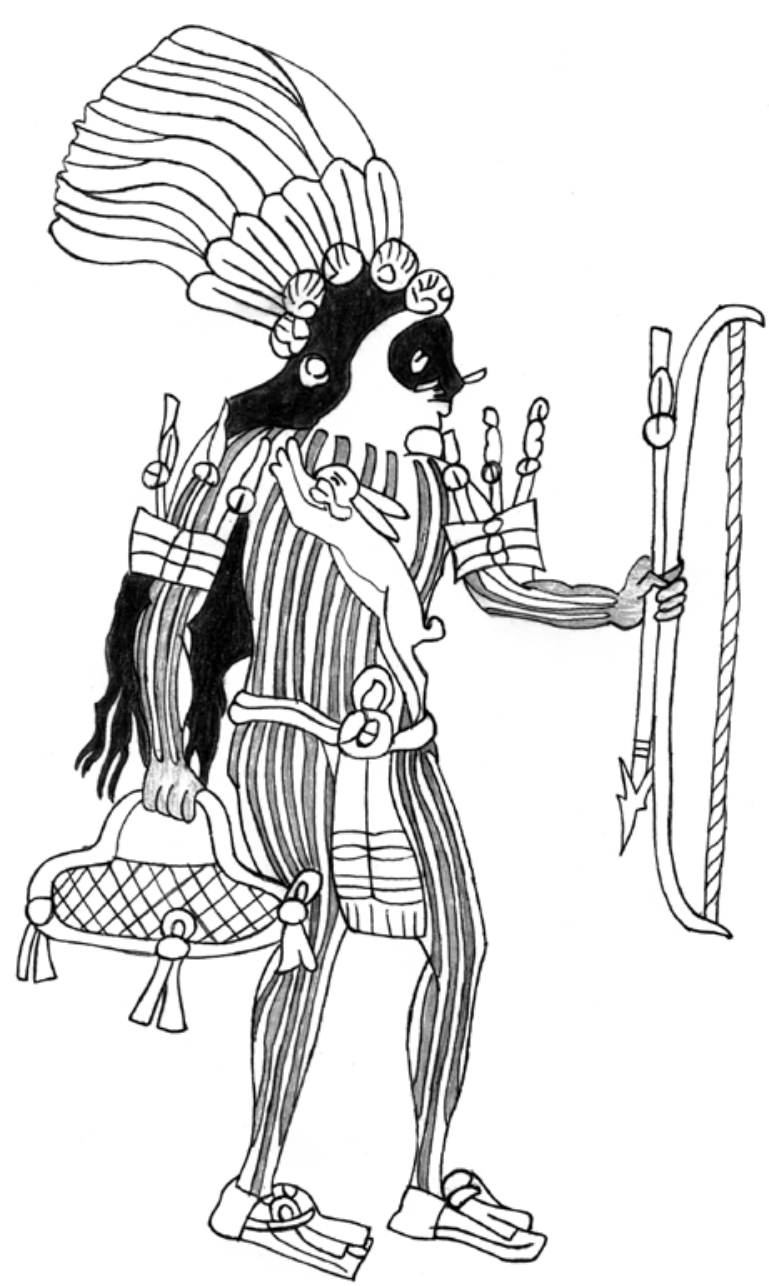

FiguRA 2 - Camaxtli armado con arco y flecha. En la mano derecha lleva el chitatli, la cesta para cargar las presas de caza. De nuevo, lleva pintura corporal rayada. Dibujo basado en Durán (1967, I: lámina 13).

Xiuhtilmatli significa "manta de turquesa". Es una prenda de forma rectangular hecha de algodón, decorada con mosaico de turquesa. Se usaba atada al hombro sobre el maxtlatl. Xiuhuitzolli significa "diadema real de turquesa". Es un objeto en forma de diadema terminado en punta, decorado con mosaico de turquesa, similar a la mitra usada por los obispos y otras dignidades religiosas. Era usada por varios gobernantes nahuas del centro de México a modo de corona. 
A estos supuestos agregamos que se buscaba reforzar el vínculo con Camaxtli, motivo por el que se entregaban al tecuhtli sus distintivos característicos, el arco y las flechas (véase la figura 2). Esto cobra sentido cuando Muñoz Camargo describe el origen de los tlaxcaltecas: "desde su origen y antigüedad, fueron los naturales desta tierra belicosísimos guerreros, porque era gente advenediza, que los llamaban chichimecas por su denuedo y ferocidad, que, por guerras y fuerza de armas, ganaron y ocuparon lo mejor y más fértil y fuerte de esta provincia" (1984: 97).

Motolinía menciona la banda de cuero rojo que se colocaba en la cabeza de los tetecuhtin, que también aparece en la frente de los gobernantes representados en la Historia tolteca-chichimeca (Kirchhoff, Güemes y Reyes, 1976: f. 21r). Este elemento formaba parte de los atavíos de Mixcóatl-Camaxtli (Olivier, 2015: 504). Cuando los tetecuhtin recibían este distintivo, con el arco y las flechas, se reforzaba su vínculo con el dios, pues al ostentar sus insignias quizá se convertían en sus representantes. El uso de esta banda también significa el reconocimiento del nuevo tecuhtli como miembro del grupo dirigente y guerrero distinguido (2015: 503). Al recibir distintivos relacionados con la guerra, característicos de su dios patrono, tal vez se concebía al nuevo tecuhtli como un guerrero destacado similar a Camaxtli.

El Lienzo de Tepeticpac, elaborado en ese altepetl de Tlaxcala aproximadamente en 1537 (Aguilera, 1986: 14, 18), representa a varios tetecuhtin que portan los atavíos mencionados por Motolinía: un arco, una flecha, la banda en la frente y el adorno de plumas en la cabeza (véase la figura 3). Cabe señalar que el tecuhtli de la figura 3 y otros personajes del lienzo llevan un tocado de dos plumas muy parecido al de Camaxtli, es decir, el cuauhpilolli, que se distingue por dos plumas grandes juntas y oscuras (Aguilera, 1998: 89; véase la figura 1). Esto permite proponer de nuevo que los tetecuhtin pudieron ser concebidos como representantes de Camaxtli, pues llevaban sus atavíos característicos.

La banda roja también era un atavío solar; a Nanauatzin, el dios que se convirtió en Sol en Teotihuacan, se le ató una cinta roja en la cabeza cuando fue instaurado como el astro (Olivier, 2015: 505). Por otra parte, las flechas que recibían los tetecuhtin también pueden relacionarse con el Sol, considerado un numen flechador, pues sus rayos eran asimilados a flechas (Limón, 2012: 119). Otra posibilidad es que las flechas también se relacionaran con Tlahuizcalpantecuhtli, deidad guerrera y flechadora (Leyenda de los soles, 1945: 122). Como se mencionó, la pintura corporal rayada era propia de Camaxtli, y las flechas y lanzadardos lo vinculaban con la guerra.

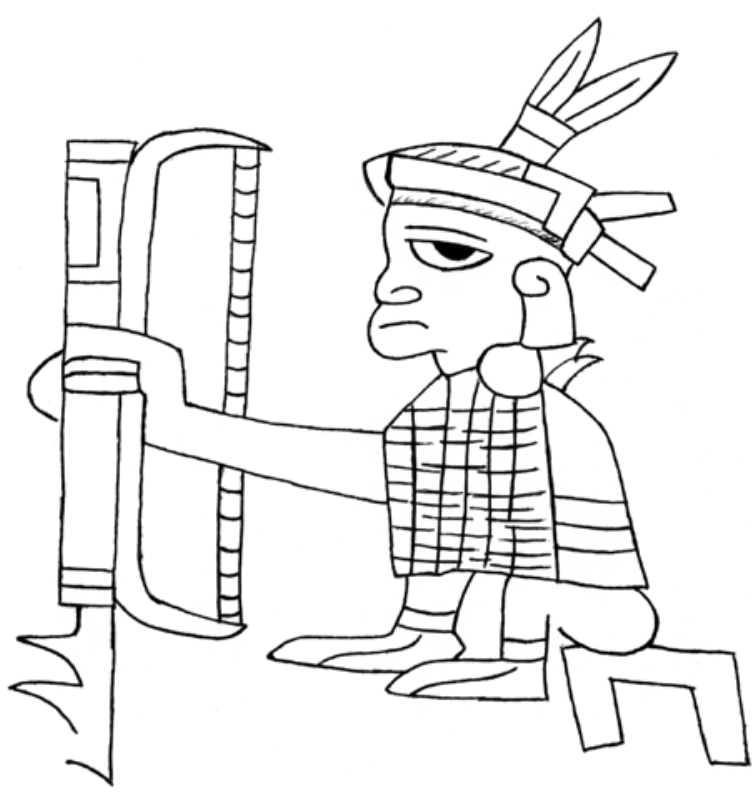

FIgURA 3 - Representación de un tecuhtli en el Lienzo de Tepeticpac. Lleva arco, flecha, una banda en la frente y un tocado con dos plumas, similar al cuauhpilolli de Camaxtli. Dibujo basado en Aguilera (1998: lienzo uno, lado derecho). 
No es de extrañar el dominio de Camaxtli durante el rito, pues los tetecuhtin le debían su posición, territorio y oficio. Además, no usaban atavíos de turquesa, como los nahuas de la cuenca de México, sino distintivos usados por su dios patrono. Motolinía menciona que luego de ser investido frente al dios, se le daba una plática al tecuhtli en la que se le pedía que tratara bien a sus gobernados (1971: 342). Después comenzaba la última fase del rito.

\section{Celebración}

Tras haber recibido su título, el tecuhtli realizaba costosas fiestas en el templo de Camaxtli, en las que se distribuía comida y regalos a los asistentes (Motolinía, 1971: 342; Muñoz, 1984: 150; Carrasco, 1966: 138). Los cronistas no dicen cuánto duraba la fiesta, tal vez cuatro días como en el caso mexica, pero no es posible asegurarlo. En los documentos no se mencionan sacrificios humanos en honor del dios patrono, como sucedía en Tenochtitlan.

Entre los mexicas, era necesario que el nuevo tlatoani emprendiera una guerra en la que debía capturar guerreros para ofrendarlos a Huitzilopochtli en su fiesta de confirmación. Parece que los tlaxcaltecas no seguían esta práctica; sin embargo, al describir la ocasión en que se "armó caballero" al hijo de Maxixcatzin, Cervantes de Salazar menciona que un guerrero tlaxcalteca le lanzó con fuerza el corazón de un espía sacrificado, procedente del pueblo de Tepeaca. Acto seguido, el mismo guerrero le dio una "recia bofetada" que le dejó la marca de los dedos ensangrentados en la cara. Según el cronista, con esto se probaba el valor del joven en la batalla (1985: 533-534). Este pasaje sugiere que sí pudo haberse llevado a cabo algún sacrificio humano en algún momento del rito en honor a Camaxtli.
Una vez concluido el rito, el nuevo tecuhtli adquiría la obligación de participar en la guerra, la impartición de justicia y las ceremonias religiosas, pues a partir de ese momento tenía que velar por el bienestar de las personas que estaba a punto de gobernar.

\section{Reflexiones finales}

Ahora explicaremos por qué el rito seguía esas fases. Primero, era necesario que comenzara en el templo del dios patrono, pues gracias a la actividad guerrera que les legó, los tlaxcaltecas consiguieron un territorio; además, los condujo desde Chicomoztoc hasta su lugar de asentamiento definitivo. Al reconocer a este numen como su beneficiario principal, es posible que los tetecuhtin empezaran el rito en su templo como agradecimiento por sus favores y para fortalecer su vínculo con él. También era necesaria la presencia del dios del fuego, para que el elemento ígneo cambiara el estado del tecuhtli y lo ayudara a comunicarse con los dioses mediante las ofrendas arrojadas a las llamas.

Una vez presentado, el tecuhtli debía ejecutar actividades penitenciales como parte de su transformación, como ayunos y autosacrificios. El tecuhtli debía comprobar su fortaleza antes de entregarle los distintivos del poder, es decir, debía demostrar que era capaz de soportar las actividades penitenciales establecidas por los dioses durante un año. Quizá la estancia de cuatro días en el tlamacazcacalco se relacionaba con el nacimiento del Sol, pues el astro tardó cuatro días en ser creado. Para que pudiera nacer, el dios que se transformó en él ayunó y se autosacrificó. Los tetecuhtin seguían esos preceptos en su estancia en ese lugar.

Durante parte de su penitencia, el tecuhtli estaba pintado de negro para resaltar su estado penitente y tal vez para recibir la energía de los dioses Tezcatlipoca y Quetzalcóatl, pues ése era su color 
característico. Estos númenes estaban vinculados a la deidad suprema Ometéotl, también conocido como Tonacatecuhtli y Tonacacihuatl (LeónPortilla, 1983: 154). Tezcatlipoca y Quetzalcóatl se desprendieron de esa deidad cuando fueron engendrados por ella, así como Tlatlauhqui Tezcatlipoca, otro de sus hijos, conocido como Camaxtli (HMP, 1965: 23). Luego de analizar los textos en náhuatl del Códice florentino, Miguel León-Portilla (1983: 164-178) concluyó que otros nombres de Ometéotl eran Quetzalcóatl y Tloque Nahuaque, otro nombre de Tezcatlipoca. El hecho de que Camaxtli se mencione como uno de sus hijos primigenios sugiere que para los tlaxcaltecas era una de las manifestaciones de la deidad suprema.

Es probable que los tetecuhtin fueran embijados de negro para ser asimilados con Tezcatlipoca y Quetzalcóatl, pues los nahuas pensaban que de estos dioses provenía el poder de los gobernantes. La gente de linaje reconocía a Quetzalcóatl como fundador de las dinastías de todos los gobernantes en los señoríos de Mesoamérica, mientras Tezcatlipoca se consideraba el dueño de los estratos celestes, de todo cuanto había en la tierra y la región de los muertos (León-Portilla, 1999: 148). Bernardino de Sahagún (1991: 31-32) menciona que era el dios que otorgaba y retiraba la riqueza y los señoríos a quien él quería, cuando lo deseaba. Se puede pensar que él también daba y quitaba el poder de los gobernantes cuando quería.

Si se acepta que los tlaxcaltecas, como otros grupos nahuas del Altiplano Central, concebían a esos dioses como otorgadores del poder, sugerimos que los tetecuhtin tiznaban sus cuerpos de negro para comunicarse con ellos y apropiarse de sus virtudes, como la fortaleza para soportar las actividades penitenciales.
Cuando el tecuhtli había completado su ardua penitencia de un año, podía recibir las insignias de poder. Camaxtli se manifestaba de nuevo en esta parte, pues los distintivos que recibía el tecuhtli pertenecían al dios. Con esta entrega, se reforzaba el vínculo con el numen, el tecuhtli se transformaba en un guerrero destacado igual que él. Por último, cuando recibía su nuevo título y las insignias que lo acreditaban como miembro del grupo dirigente, empezaba el festejo por haber concluido sus pruebas de manera satisfactoria.

Durante el rito se resaltaban los ideales guerreros y la preocupación por rendir culto a deidades vinculadas con el sol, la tierra, la lluvia y la guerra, como se deduce por la presencia de los dioses Camaxtli — vinculado a Tlahuizcalpantecuhtli-, Tezcatlipoca, Xiuhtecuhtli, Xipe Tótec y Matlalcueye. La importancia de la guerra entre los tlaxcaltecas se manifestaba no sólo por la presencia de sus dioses, también porque los tetecuhtin recibían armas para practicarla y se les perforaba la nariz con garras de águila y jaguar, animales relacionados con los guerreros.

La presencia de Xiuhtecuhtli y Matlalcueye muestra la importancia de las deidades relacionadas con los elementos indispensables para asegurar la vida de los seres humanos: la luz y el calor del sol, la lluvia para la agricultura y los alimentos proporcionados por la tierra. Al ofrendar su sangre frente al brasero y en la montaña con el nombre de la diosa, es posible que el tecuhtli les pidiera que siguieran concediendo estos beneficios. Se aprecia que los tlaxcaltecas compartían con otros grupos mesoamericanos las concepciones referentes al sol, la tierra y la guerra, es decir, alimentarlos con sangre obtenida del autosacrificio y cautivos de guerra, de ahí la importancia de esta actividad. D 


\section{Bibliografía}

Acuña, René, 1984, “Introducción”, en René Acuña (ed.), Relaciones geográficas del siglo xvI: Tlaxcala, t. I, Universidad Nacional Autónoma de México, México, pp. 7-22.

Aguilera, Carmen, 1986, Lienzos y Códice de Tepeticpac, Instituto Tlaxcalteca de la Cultura, Tlaxcala.

, 1998, Lienzos de Tepeticpac, Gobierno del Estado de Tlaxcala, Tlaxcala.

Benavente, Toribio de (Motolinía), 1971, Memoriales o Libro de las cosas de la Nueva España y de los naturales de ella, Edmundo O’Gorman (ed.), Universidad Nacional Autónoma de México, México.

Carrasco, Pedro, 1966, "Documentos sobre el rango de tecuhtli entre los nahuas tramontanos", Tlalocan, vol. 5, núm. 2, pp. 133-160. , 2000, "Cultura y sociedad en el México antiguo", en Historia general de México, El Colegio de México, México, pp. 153-233.

Cervantes de Salazar, Francisco, 1985, Crónica de la Nueva España, Porrúa (Biblioteca Porrúa 84), México.

Códice Borgia, s. f., en Fundación para el Avance de los Estudios Mesoamericanos. Disponible en línea <http://www.famsi.org/spanish/ research/loubat/Borgia/thumbsO.html>.

Cortés, Hernán, 1960, Cartas de relación, Porrúa (Sepan cuantos... 7), México.

Díaz del Castillo, Bernal, 1960, Historia verdadera de la conquista de la Nueva España, Porrúa (Sepan cuantos... 5), México.

Durán, Diego, 1967, Historia de las Indias de Nueva España e islas de la tierra firme, 2 t., Ángel M. Garibay K. (ed.), Porrúa (Biblioteca Porrúa de Historia), México.

Durkheim, Émile, 1992, Las formas elementales de la vida religiosa, Akal, Madrid.

Eliade, Mircea, 1972, Tratado de historia de las religiones, Era, México.

García Cook, Ángel y Leonor Merino Carrión, 1997, "Integración y consolidación de los señoríos en Tlaxcala, siglos IX al XVI”, en Lorena Mirambell (coord.), Antología de Tlaxcala, vol. 4, Instituto Nacional de Antropología e Historia/Gobierno del Estado de Tlaxcala, México, pp. 231-249.

García Martínez, Bernardo, 2011, "Microciudades al por mayor. Las congregaciones de pueblos en el siglo xvı”, en Arqueología Mexicana, núm. 107, pp. 66-71.

Gibson, Charles, 1991, Tlaxcala en el siglo xvı, Gobierno del Estado de Tlaxcala/Fondo de Cultura Económica, México.

Harris, Marvin, 1990, Antropología cultural, Alianza, Madrid.

Historia de los mexicanos por sus pinturas (HMP), 1965, en Ángel María Garibay K. (ed.), Teogonía e historia de los mexicanos. Tres opúsculos del siglo XVI, Porrúa (Sepan cuantos... 37), México, pp. 23-90.

Kirchhoff, Paul, Lina Odena Güemes y Luis Reyes García, 1976, Historia tolteca-chichimeca, Instituto Nacional de Antropología e Historia/ Secretaría de Educación Pública, México.

León-Portilla, Miguel, 1983, La filosofía náhuatl estudiada en sus fuentes, Universidad Nacional Autónoma de México, México.

, 1999, “Ometéotl, el supremo dios dual, y Tezcatlipoca 'dios principal”, en Estudios de Cultura Náhuatl, vol. 30, pp. 133-152.

Leyenda de los soles, 1945, en Códice Chima/popoca, Primo Feliciano Velázquez (trad.), Universidad Nacional Autónoma de México, México, pp. 119-128.

Lienzo de Tlaxcala, 2016, en Andrea Martínez Baracs, “La Tlaxcala virreinal”, en Arqueología Mexicana, núm. 139, pp. 66-73.

Limón Olvera, Silvia, 2012, El fuego sagrado. Simbolismo y ritualidad entre los nahuas, Universidad Nacional Autónoma de México-Centro de Investigaciones sobre América Latina y del Caribe, México.

Lockhart, James, 1999, Los nahuas después de la Conquista. Historia social y cultural de los indios del México central, del siglo XVI al xVIII, Fondo de Cultura Económica, México.

López Austin, Alfredo, 1985, La educación de los antiguos nahuas, 2 t., Secretaría de Educación Pública/Ediciones el Caballito, México.

— - 1994, Tamoanchan y Tlalocan, Fondo de Cultura Económica, México.

Maisonneuve, Jean-Louis, 1991, Ritos religiosos y civiles, Herder, Barcelona.

Molina, Alonso de, 1970, Vocabulario en lengua castellana y mexicana y mexicana y castellana, Porrúa (Biblioteca Porrúa 44), México.

Muñoz Camargo, Diego, 1984, "Descripción de la ciudad y provincia de Tlaxcala de la Nueva España e indias del mar océano para el buen gobierno y ennoblecimiento de ellas, mandada hacer por la S.C.R.M. del rey don Felipe, Nuestro Señor”, en René Acuña (ed.), Relaciones geográficas del siglo xvI: Tlaxcala, t. I, Universidad Nacional Autónoma de México, México. 
Nava Román, María del Rosario, 2009, El color negro en la piel y su poder político-religioso en el mundo mesoamericano: del Altiplano Central a la Mixteca, tesis de maestría en historia del arte, Universidad Nacional Autónoma de México-Facultad de Filosofía y Letras, México.

Olivier, Guilhem, 2015, Cacería, sacrificio y poder en Mesoamérica. Tras las huellas de Mixcóatl, "Serpiente de Nube", Fondo de Cultura Económica/Universidad Nacional Autónoma de México/Fideicomiso Felipe Teixidor y Montserrat Alfau de Teixidor/Centro de Estudios Mexicanos y Centroamericanos, México.

Sahagún, Bernardino de, 1991, Historia general de las cosas de Nueva España, Ángel María Garibay K. (ed.), Porrúa (Sepan cuantos... 300), México.

Soustelle, Jacques, 1982, El universo de los aztecas, Fondo de Cultura Económica, México.

Sullivan, Thelma, 2014, Compendio de la gramática náhuatl, Universidad Nacional Autónoma de México, México.

Thouvenot, Marc, 2008, "La noción de teuctli", en Guilhem Olivier (coord.), Símbolos de poder en Mesoamérica, Universidad Nacional Autónoma de México, México, pp. 47-65. 